\title{
Paul Verlaine, Correspondance générale
}

\section{Mario Richter}

\section{(2) OpenEdition}

\section{Journals}

\section{Edizione digitale}

URL: http://journals.openedition.org/studifrancesi/30631

DOI: 10.4000/studifrancesi.30631

ISSN: 2421-5856

\section{Editore}

Rosenberg \& Sellier

\section{Edizione cartacea}

Data di pubblicazione: 1 avril 2006

Paginazione: 185

ISSN: 0039-2944

\section{Notizia bibliografica digitale}

Mario Richter, «Paul Verlaine, Correspondance générale», Studi Francesi [Online], 148 (XLX | I) | 2006,

online dal 30 novembre 2015, consultato il 18 avril 2021. URL: http://journals.openedition.org/ studifrancesi/30631; DOI: https://doi.org/10.4000/studifrancesi.30631

\section{Questo documento è stato generato automaticamente il 18 avril 2021.}

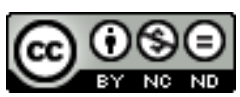

Studi Francesi è distribuita con Licenza Creative Commons Attribuzione - Non commerciale - Non opere derivate 4.0 Internazionale. 


\title{
Paul Verlaine, Correspondance générale
}

\author{
Mario Richter
}

\section{NOTIZIA}

PAUL VERLAINE, Correspondance générale, I 1857-1885, établie et annotée par Michael

Pakenham, Paris, Fayard, 2005, pp. 1122.

1 Dopo le monumentali edizioni dei carteggi di Théophile Gautier e di Emile Zola, gli studiosi della seconda metà del XIX secolo possono ora salutare con grande soddisfazione la pubblicazione del primo tomo della corrispondenza generale di Verlaine, che raggiungerà nel suo complesso la consistenza di circa 2000 lettere.

2 Questo primo volume è particolarmente prezioso perché porta luce sugli anni della formazione del poeta, sulla sua progressiva affermazione, sui suoi rapporti con Rimbaud, sulla sua vita in prigione, sulla sua conversione, sulle sue amicizie, sui suoi progetti, sulla sua opera e sulle sue idee letterarie.

3 Le lettere di Verlaine erano note tramite le raccolte parziali e soprattutto grazie alla Correspondance de Verlaine (1922-1929, ristampata da Slatkine nel 1983) curata da Adolphe Van Bever. Tuttavia la parzialità delle prime e il carattere tutt'altro che ineccepibile della seconda hanno reso necessaria l'impresa alla quale ha finalmente atteso con encomiabile dedizione e con le migliori regole dell'arte uno specialista del valore di Michael Pakenham.

4 Il lettore si trova di fronte a testi completamente rivisti e, all'occorrenza, corretti dal curatore con filologica precisione, integrati nell'ordine cronologico dalle lettere che furono indirizzate al poeta. Vi sono inoltre riprodotti i numerosi e significativi disegni presenti nelle stesse missive. L'apparato di note che correda ogni lettera risponde con sobria chiarezza a tutti gli interrogativi - di natura storica o aneddotica, culturale o letteraria - che via via sollevano questi testi. 
5 Il volume si conclude con una utilissima riproduzione, in ordine cronologico, delle recensioni e degli articoli dedicati alle opere di Verlaine, nonché da un repertorio dei corrispondenti (con esaurienti informazioni), da una bibliografia delle principali opere consultate e da un accurato indice analitico.

6 Strumento indispensabile per chiunque voglia conoscere e studiare correttamente Verlaine e la sua opera. 